\title{
Embedding CSR in the Firm's DNA, The Case for Strategic CSR in Emerging Markets: An Abstract
}

\author{
Cezara Nicoara, Dayananda Palihawadana, Matthew Robson, \\ and Constantinos Leonidou
}

Building on insights from stakeholder and social capital theory, we investigate into the conditions and processes through which the subsidiaries of MNEs in emerging markets create organizational value by leveraging strategic CSR. Seeing how current research is almost exclusively dominated by confirming the link between social responsibility and financial performance, with our study, we plan to depart from this debate to look at broader value-creating parameters. From this perspective, we apply a tailored designed survey method to focus on Romania, one of Eastern Europe's emerging economies. This research contributes to marketing and international business literature by advancing the knowledge on the determinants and the stages of deploying strategic CSR (formation, implementation, and control). We also highlight the neglected role of the MNE-subsidiary relationships in understating CSR in emerging markets.

References Available Upon Request

C. Nicoara $(\varangle) \bullet$ D. Palihawadana $\bullet$ M. Robson $\bullet$ C. Leonidou

Leeds University Business School, Leeds, UK

e-mail: bn12c2n@leeds.ac.uk; dp@lubs.leeds.ac.uk; mjro@lubs.leeds.ac.uk;

C.Leonidou@leeds.ac.uk 